\title{
HPLC-ESI-MS/MS ASSESSMENT OF THE TETRAHYDRO-METABOLITES OF CORTISOL AND CORTISONE IN BOVINE URINE: PROMISING MARKERS OF DEXAMETHASONE AND PREDNISOLONE TREATMENT
}

\section{Chiesa, S. Panseri, R. Pavlovic, F.T. Cannizzo, B. Biolatti, S. Divari, R Villa \& F.} Arioli

To cite this article: L. Chiesa, S. Panseri, R. Pavlovic, F.T. Cannizzo, B. Biolatti, S. Divari, R Villa \& F. Arioli (2016): HPLC-ESI-MS/MS ASSESSMENT OF THE TETRAHYDRO-METABOLITES OF CORTISOL AND CORTISONE IN BOVINE URINE: PROMISING MARKERS OF DEXAMETHASONE AND PREDNISOLONE TREATMENT, Food Additives \& Contaminants: Part A, DOI: $10.1080 / 19440049.2016 .1202453$

To link to this article: http://dx.doi.org/10.1080/19440049.2016.1202453

Accepted author version posted online: 16 Jun 2016.

Published online: 16 Jun 2016.

Submit your article to this journal

View related articles $\sqsubset$

View Crossmark data 
Publisher: Taylor \& Francis

Journal: Food Additives \& Contaminants: Part A

DOI: $10.1080 / 19440049.2016 .1202453$

HPLC-ESI-MS/MS ASSESSMENT OF THE TETRAHYDRO-METABOLITES OF CORTISOL AND CORTISONE IN BOVINE URINE: PROMISING MARKERS OF DEXAMETHASONE AND PREDNISOLONE TREATMENT

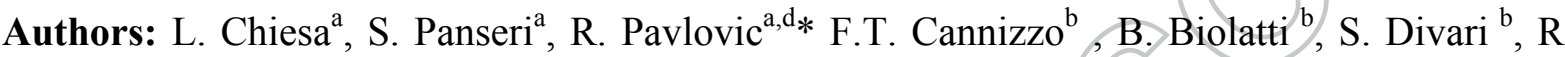
Villa $^{\mathrm{c}}, \mathrm{F}$. Arioli ${ }^{\mathrm{c}}$

a Department of Veterinary Science and Public Health, University of Milan, Via Celoria 10, 20133 Milan, Italy

${ }^{\mathrm{b}}$ Department of Veterinary Science, University of Turin, Largo Braccini 2, 10095 Grugliasco, Italy

${ }^{c}$ Department of Health, Animal Science and Food Safety, University of Milan, Via Celoria 10, 20133 Milan, Italy

${ }^{\mathrm{d}}$ Department of Chemistry, Faculty of Medicine, University of Nis, Bulevar Dr Zorana Djindjica 81, 18000, Nis, Serbia

*Corresponding author: Radmila Pavlovic, Department of Veterinary Science and Public Health, University of Milan, Via Celoria 10, 20133 Milan, Italy

E-mail:radmila.pavlovic1@unimi.it

\section{Abstract}

The effects of long-term administration of low doses of dexamethasone (DX) and prednisolone (PL) on the metabolism of endogenous corticosteroids were investigated in veal calves. In addition to cortisol (F) and cortisone (E), whose interconversion is regulated by $11 \beta$-hydroxysteroid dehydrogenases (11ßHSDs), special attention was paid to tetrahydrocortisol (THF), allo-tetrahydrocortisol (aTHF), 
tetrahydrocortisone (THE) and allo-tetrahydrocortisone (aTHE), that are produced from $\mathrm{F}$ and $\mathrm{E}$ by catalytic activity of $5 \alpha$ and $5 \beta$ reductases. A specifically-developed HPLC-ESI-MS/MS method achieved the complete chromatographic separation of two pairs of diastereoisomers (THF/aTHF and THE/aTHE) which, with appropriate mass fragmentation patterns, provided an unambiguous conformation. The method was linear $\left(\mathrm{r}^{2}>0.9905 ; 0.5-25 \mathrm{ng} \mathrm{mL}^{-1}\right)$, with LOQQ of $0.5 \mathrm{ng} \mathrm{mL} \mathrm{mL}^{-1}$. Recoveries were in range $75-114 \%$, while matrix effects were minimal.

The experimental study was carried out on three groups of male Friesian veal calves group PL ( $\mathrm{n}=6$, PL acetate $15 \mathrm{mg}$ /day p.o. for 31 days); group DX ( $=5,5 \mathrm{mg}$ of estradiol (E2) i.m., weekly, and 0.4 $\mathrm{mg} /$ day of DX p.o. for 31 days) and a control group $(\mathrm{n}=8)$. Urine was collected before, during (twice) and at the end of treatment. During PL administration, the tetrahydro-metabolite levels decreased gradually and remained low after the suspension of treatment. DX reduced urinary THF that persisted after the treatment, while THE levels decreased during the experiment, but rebounded substantially after the DX was withdrawn. Both DX and PL significantly interfered with production of $\mathrm{F}$ and $\mathrm{E}$, leading to their complete depletion. Taken together, our results demonstrate the influence of DX and PL administration on $11 \beta$ HSD activity and their impact on dysfunction of the 5-reductase pathway. In conclusion, profiling tetrahydro-metabolites of $\mathrm{F}$ and E might serve as an alternative, indirect but reliable, non-invasive procedure for assessing the impact of synthetic glucocorticosteroids administration. 


\section{INTRODUCTION}

Endogenous corticosteroids, mineralocorticoids and glucocorticoids, represent an essential physiological class of steroidal structures that are synthesised in the adrenal cortex. These hormones are involved in a wide range of pathophysiological processes, such as the stress response, inflammation, immune function, hydro-electrolyte balance, reproduction and behaviour (Vincenti, et al. 2012). The most important glucocorticosteroid is cortisol (F), which exhibits hormonal activity; whereas, cortisone $(\mathrm{E})$ is the inactive hormone that is produced from $\mathrm{F}$ by $11 \beta$-hydroxysteroid

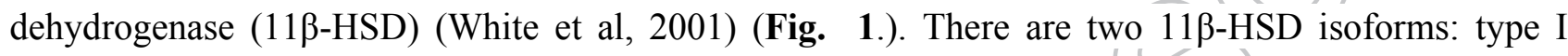
triggers the conversion of $\mathrm{E}$ into $\mathrm{F}$, while type II regulates the conversion of $\mathrm{F}$ into $\mathrm{E}$. F and $\mathrm{E}$ are metabolized to the corresponding A-ring reduced metabolites: tetrahydrocortisol (THF), allotetrahydrocortisol (aTHF), tetrahydrocortisone (THE) and allo-tetrahydrocortisone (aTHE) by a twostep reduction, firstly of the delta 4 double bond, catalyzed by $5 \alpha$ - or $5 \beta$-reductase, followed by the reduction of the 3-keto group, catalyzed by 3-oxoreductase (Draper \& Stewart, 2005). Studies on human urine have shown that the F/E ratio can be used as a marker of inhibition of 11ß-HSD type II (Tomlinson et al. 2007), while the (THF + aTHF)/THE ratio can be considered a marker of inhibition of 11ß-HSD type I (Raffaelli et al. 2006; Courtney et al. 2008).

However, due to the important role of natural corticosteroids in several bodily functions, they also have been exogenously administered to animals and humans in order to obtain health benefits and also to improve physical and growth performance. This has led to the chemical synthesis of corticosteroids with increased activity, for example, prednisolone (PL) and dexamethasone (DX). Introduction of a double bond in position $\mathrm{C} 1-\mathrm{C} 2$ of $\mathrm{F}$ and the formation of a conjugated $\pi$-electronic system of prednisolone results in significantly increased pharmacological activity extending the duration of glucocorticosteroid therapeutic effects. DX is a C9-fluorinated and C16-methylated PL derivative, characterized by pronounced glucocorticoid efficacy associated with a nearly complete loss of mineralcorticoid activity.

Data from the Italian National Residues Plan (PNR) showed an increase in illegal use of DX, while particular attention was drawn to PL, as this corticosteroid may, in certain metabolic conditions, be produced endogenously (Arioli et al. 2010; Pompa et al. 2011). However, the persistent use of these substances requires a permanent commitment of public veterinary services for their prevention and 
control. For this purpose, different analytical methods are commonly used, but the only method that is legally recognized is direct chemical analysis of the administrated substances, which, although specific and sensitive, has some limitations. Furthermore, the very quick biotransformation of PL and DX and very low dosage makes their detection particularly difficult. Therefore, new methodological approaches to reinforce veterinary controls are urgently needed (Cannizzo et al. 2011; Divari et al. 2011; Vascellari et al. 2012; Pegolo et al. 2015, Pirro et al. 2015).

Focusing on the veterinary field, the most desirable action of hormones has always been to increase the economic benefit by reducing the costs and obtaining more products of animal origin with shorter production times. Synthetic corticosteroids administered to bovines, results in an improved feed conversion ratio and produce an increase in live weight. This effect probably depends on their direct action as glucocorticoids and on their interference with endogenous F synthesis and metabolism (Möstl et al. 1999). Quinkler et al. (2003) showed that activity of the "cortisol-cortisone shuttle" system is influenced by the presence of exogenous glucocorticoids, like DX and PL.

The effects of administration of synthetic corticosteroids on the urinary profile of $\mathrm{F}$ has been investigated in humans in detail (Mazzarino et al. 2006). On the other hand, few studies have been devoted to investigate the correlation between natural and administered synthetic corticosteroids in order to identify indirect biomarkers for eventual treatments (Savu et al. 1996; Vincenti et al. 2009; Capolongo et al. 2007; Ferranti et al. 2011; Vincenti et al. 2012; Ferranti et al. 2013; Nebbia et al. 2014). Therefore, a method to identify natural corticosteroid levels in bovines could be an important tool for the control of illicit corticosteroid treatment in livestock production. Recently, we have published (Pavlovic et al. 2013) that PL treatment influenced 11ß-HSD, which brought up questions about the impact of PL treatment on the THF and THE metabolic rates. Accordingly, the role and importance of reduced forms of $\mathrm{F}$ and $\mathrm{E}$ and their metabolic rates during treatment with exogenous glucocorticoids are lacking and remain to be established.

In order to better understand the biological relevance of cattle's $11 \beta$-HSDs and their activity in response to treatment with synthetic corticosteroids, it would be necessary to establish baseline levels of the endogenous corticosteroids. Remarkably, not many studies about the concentrations of $\mathrm{F}$ and $\mathrm{E}$ in bovine urine are present in the literature (Antignac et al. 2002; Pavlovic et al. 2012; Ferranti et al. 2013). In addition, due to their low concentrations, synthetic and/or (pseudo)natural corticosteroids are often not detectable in biological matrices by official methods. For both purposes, a highly sensitive and selective analysis is required. Our study was focused on the development of a quantitative HPLC- 
ESI-MS/MS method for simultaneous measurement of F, E, THF, aTHF, THE, aTHE, PL, Prednisone, $(\mathrm{PN})$ and DX in bovine urine. Our analytical procedure could then be used to make a preliminary estimate of the effects of PL and DX administration on the amounts and corresponding ratios of targeted natural corticosteroids. This would consequently allow an evaluation of the utility of their quantification in studying either the activity of the enzymes responsible for their interconversion or any possible application to revealing the abuse of synthetic corticosteroids in bovine agriculture. This might be considered an important tool, which can be used for exposing illegal use of corticosteroids.

\section{MATERIALS AND METHODS}

\subsection{Chemicals and reagents}

F, E, PL, PN and DX were purchased from Sigma-Aldrich (St. Louis, MO, USA) while THF, aTHF, THE and aTHE were obtained from Steraloids, Inc. (Newport, RI, USA). The internal standard PL-d6 (PL-d6) was from CDN Isotopes (Pointe-Claire, Quebec, Canada). All other chemicals were from Fluka Chemie GmbH (Buchs, Switzerland). Ultrapure water was obtained through a Milli-Q system (Millipore, Molsheim, France). Standard stock solutions were prepared in methanol (1 mg/mL) and stored at $-40{ }^{\circ} \mathrm{C}$. Working solutions were prepared daily by diluting the stock solutions with a methanol/water (50:50, v/v) mixture. Roche Diagnostics GmbH (Boehringer Mannheim, Germany) supplied beta-glucuronidase from Escherichia coli $\mathrm{K} \quad 12$ (EC 3.2.1.31) and $\beta$ glucuronidase/arylsulfatase from Helix pomatia (EC 3.2.1.31 / EC 3.1.6.1).

\subsection{Sample preparation}

The sample purification was analogous to that previously established for human urine by Cuzzola et al. (2009) with slight modifications regarding bovine urine (Pavlovic et al. 2012). Briefly, a $1 \mathrm{~mL}$ aliquot of filtered urine was diluted with $2 \mathrm{~mL}$ phosphate buffer $(0.2 \mathrm{M}, \mathrm{pH} 6.2)$ and incubated with $40 \mu \mathrm{L} \beta$-glucuronidase from E.coli at $55^{\circ} \mathrm{C}$ for $4 \mathrm{~h}$. Alternatively, during preliminary experiment we performed deconjugation with $20 \mu \mathrm{L}$ of $\beta$-glucuronidase/sulphatase from Helix pomatia at $45^{\circ} \mathrm{C}$ for $4 \mathrm{~h}$. After cooling down to room temperature, $20 \mu \mathrm{L}$ of $0.1 \mu \mathrm{g} / \mathrm{mL}$ internal standard was added for a final concentration of $2 \mathrm{ppb}$. Each sample was extracted using an Oasis HLB cartridge (3 mL, $60 \mathrm{mg}$, Waters) with Supelco SPE vacuum manifold. The HLB columns were conditioned by passage of $2 \mathrm{~mL}$ methanol followed by $2 \mathrm{~mL}$ water. The sample was deposited on the column and washed first with $2 \mathrm{~mL}$ of $10 \%$ methanol and then with $1 \mathrm{~mL}$ of $2 \%$ ammonia in $50 \%$ methanol. The elution to recover 
the corticosteroids of interest was performed with $2 \mathrm{~mL}$ of methanol. The eluate was evaporated under a stream of nitrogen and reconstituted in $1 \mathrm{~mL}$ of initial mobile phase.

\subsection{LC-MS/MS instrumentation and analytical conditions}

LC-MS/MS analysis was carried out on a Thermo Finnigan HPLC system (Thermo Fisher, San Josè, CA, USA), consisting of a Surveyor MS quaternary pump with a degasser, a Surveyor AS autosampler, a column oven and a Rheodyne valve with $20 \mu \mathrm{L}$ sample loop. The mass spectrometer system was a TSQ Quantum triple quadrupole (Thermo Fisher Scientific, San Jose, CA, USA) equipped with an electrospray interface (ESI) set in the negative polarity ionisation mode. The analysis was performed in multiple reaction monitoring (MRM) mode. Acquisition data were recorded and elaborated using Xcalibur ${ }^{\mathrm{TM}}$ software from Thermo.

Chromatographic separation was achieved using a Raptor (Restek) biphenyl column (150 x 2.1 $\mathrm{mm}, 2.7 \mu \mathrm{m})$ with a Raptor (Restek) biphenyl $2.7(5 \times 2.1 \mathrm{~mm})$ guard column, which was kept at $30{ }^{\circ} \mathrm{C}$. The mobile phase used in the chromatographic separation consisted of a binary mixture of solvents A (aqueous formic acid, 0.1\%), and B (100\% MeOH) at a flow rate of $200 \mu \mathrm{L} / \mathrm{min}$. The gradient program began at $75 \%$ A changing to $40 \%$ A in $20^{\text {th }}$ min. Subsequently, the mobile phase A rapidly decreased to $10 \%$ in next two minutes, which remained constant up to the $25^{\text {th }} \mathrm{min}$. The mobile phase was returned to initial conditions at $28^{\text {th }} \mathrm{min}$, with the equilibration time that included the interval from $28^{\text {th }}$ to $35^{\text {th }}$ min.

Acquisition parameters were optimised in the ion spray mode with direct continuous pumpsyringe infusion of standard solutions of the analytes at the concentration of $1 \mu \mathrm{g} / \mathrm{mL}$ at a flow rate of the syringe of $10 \mu \mathrm{L} / \mathrm{min}$ and a pump flow rate of $100 \mu \mathrm{L} / \mathrm{min}$ in the ion source of the mass spectrometer. The optimised parameters were the following: capillary voltage $4000 \mathrm{~V}$; ion transfer capillary temperature $340^{\circ} \mathrm{C}$; and sheath and auxiliary gas (nitrogen) were fixed at 30 and 10 (arbitrary units), respectively. The collision gas was argon at $1.5 \mathrm{mTorr}$ and the peak resolution of $0.70 \mathrm{Da}$ FWHM was used.

\subsection{Assay validation}

The proposed procedure was validated in order to evaluate the method in terms of specificity, linearity, sensitivity, precision, matrix effects and recovery.

\subsubsection{Specificity}

During preliminary experiments, urine from bovines that were variable in age, gender and breed were randomly analyzed. During those initial surveys, we found considerable number of samples with very low amounts (traces) of the endogenous compounds of interest: THF, THE, F and E. Furthermore, 
in some samples it was not possible to detect any of them. Those samples were considered as blank samples for the specificity evaluation. We analysed an appropriate number of representative blank samples $(\mathrm{n}=10)$ and checked for any interference (signals, peaks, ion traces) in the region of interest where the target analyte was expected to elute. The occurrence of possible interference from closely related substances (isomers, metabolites, degradation products, endogenous substances, matrix constituents) was tested by monitoring the MRM profiles of investigated compounds at the retention time intervals expected for their elution. The identification of corticosteroids performed by means of LC-MS/MS was done according to European Union guidelines (Commission Decision 2002/657/EC). The presence of the analytes being investigated was assessed by comparing the ratio of the chromatographic retention time of the analyte to that of the internal standard; the relative retention time of the analyte should correspond to that of the calibration solution at a tolerance of $\pm 2.5 \%$. Three/four transitions were monitored for each analyte with a signal-to-noise ratio greater than three. All ion ratios of compounds from real samples were within the recommended tolerances when compared with the standards. A signal-to-noise $(\mathrm{S} / \mathrm{N})$ ratio greater than 3 was considered satisfactory in order to confirm the diagnostic ions. The quantifier ion was the one with the highest $\mathrm{S} / \mathrm{N}$ value, which was not always the most abundant ion.

\subsubsection{Calibration curve preparation, linearity, and sensitivity}

A standard stock solution (1 mg/mL) of each corticosteroid was prepared in methanol. Standard spiking solutions at concentrations of $1 \mu \mathrm{g} / \mathrm{mL}$ were prepared by dilution of the stock standard solution. Bovine urine samples that in preliminary experiments did not revealed the presence of THF, THE, F and $\mathrm{E}$ were diluted with water (1:2) and exploited as blank matrices. Equal aliquots $(2 \mathrm{~mL})$ of a blank urine sample were fortified with seven different amounts of corticosteroids $(0.5,1,2.5,5,10,25$ and 50 $\left.\mathrm{ng} \mathrm{mL} \mathrm{m}^{-1}\right)$ and a constant quantity of internal standard $\left(2 \mathrm{ng} \mathrm{mL}^{-1}\right)$ was subjected to the above described procedure. The analysis was performed in triplicate. The linear calibration curves were established by employing the IS calibration method: the ratio between the peak area of the analytes and the peak area of IS was plotted on the Y-axis with scalar concentration levels of standards plotted on the X-axis, leading to the equation $\mathrm{Y}=\mathrm{m} * \mathrm{X}+\mathrm{b}$. The linear fit was verified by squared correlation coefficients $\left(\mathrm{R}^{2}\right)$. Sensitivity was determined as the lower limit of quantification (LLOQ). This parameter was calculated from the lowest point on the calibration curve under the following conditions: (1) the analyte response at the LLOQ should be at least 5 times the response compared to blank response; and (2) the analyte peak should be identifiable, discrete, and reproducible with a precision of $20 \%$ and accuracy of 80-120\% (FDA: Guidance for Industry Bioanalytical methods validation). The matrix-match 
calibration curves that served as quality control samples (QCs) were repeated and were verified at the beginning of each working session involving the analysis of urinary excretion samples.

\subsubsection{Precision and repeatability}

The overall precision was broken down into two factors: instrumental and method precision. Instrumental precision was evaluated by six injections of each analyte at concentrations of $10 \mathrm{ng} \mathrm{mL}^{-1}$ according to the optimal operative conditions. In this way, the repeatability of the instrumental system, expressed as relative standard deviations (RSD), was acquired. Method precision defined as intra-day repeatability of the assay, presented also as RSD, was determined by replicate analyses of blank urine samples $(\mathrm{n}=6)$ fortified with 2.5 and $10 \mathrm{ng} \mathrm{mL}^{-1}$ of each compound. The intermediate (inter-day) method repeatability was determined on six consecutive days by processing the same samples used for intraday-precision.

\subsubsection{Matrix effects}

The matrix effect (ME) was examined by comparing the mean peak areas of the analytes and the IS between two different series. The first series consisted of blank urine samples spiked after the

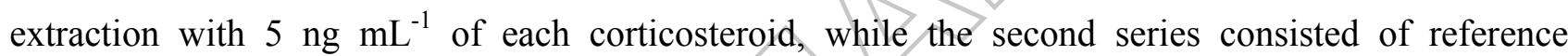
standards. The ME was defined as follows: $\mathrm{ME} \%=100 \times$ series $1 /$ series 2 , and it would indicate the possibility of ionisation suppression or enhancement for analytes and IS. An endogenous matrix effect is implied if the ratio is less than $85 \%$ or more than $115 \%$ (Matuszewski et al. 2003).

\subsubsection{Recovery}

Recovery data for all compounds were obtained in triplicate analyses of urine samples before and after adding known amounts of standards at lower $\left(2.5 \mathrm{ng} \mathrm{mL}^{-1}\right)$ and higher $\left(10 \mathrm{ng} \mathrm{mL}^{-1}\right)$ spiked concentrations. Recovery was calculated from the percentage difference between the quantitation results according to the following equation: Recovery $(\%)=100 \times\left[\mathrm{Conc}_{(\text {urine }}+\right.$ spike) $\left.-\mathrm{Conc}_{(\text {urine) }}\right] /$ $\operatorname{Conc}_{(\text {spike). }}$

\subsection{Animal study}

The study was carried out on 19 male Friesian veal calves randomly assigned to three experimental groups. Group PL $(\mathrm{n}=6)$ was administered PL acetate, $15 \mathrm{mg} / \mathrm{day}$ p.o. for 31 days; group $\mathrm{DX}(\mathrm{n}=5)$ was administered $5 \mathrm{mg}$ of estradiol (E2) i.m., weekly for six weeks, and $0.4 \mathrm{mg} /$ day of DX p.o., for 31 days starting from the second injection of E2. Group $\mathrm{C}(\mathrm{n}=8)$ was untreated. Urine was collected at days 0 (one week before treatment), 15, 29 and 40 in the early morning after spontaneous micturition by licensed veterinarians, taking care to prevent faecal contamination. The last sampling 
was carried out three days after treatment suspension. The samples were divided into aliquots and stored at $-80{ }^{\circ} \mathrm{C}$ until the analysis was performed.

\subsection{Statistical analysis}

According to the Shapiro-Wilk test, the data were not normally distributed in the majority of the groups tested, therefore, non-parametric statistical evaluations were used. The Friedman Repeated Measures Analysis of Variance on Ranks, followed by all pairwise multiple comparison procedures (Tukey's Test) were used to check the differences between the medians of the three datasets. The statistical analyses were performed using Microsoft Excel spreadsheets and Sigma Stat (Statistical Analysis System, version 12.5) statistical software package (Jandel Scientific GmbH, Erkrath, Germany). A $P$-value $<0.05$ was defined as the level of statistical significance.

\section{RESULTS AND DISCUSION}

Corticosteroids, when administered to promote the growth of food production animals, usually are given in small doses over a relatively long time period. Because of their low concentrations and the fact that there is only limited understanding of their metabolism, the determination of exogenously administered corticosteroids remains difficult and rather problematic. The question that arises is whether the absence of these substances actually means that animals were not subjected to illicit treatment during breeding. An answer on this question cannot be given with certainty; studies on the impact of synthetic analogues on metabolism of endogenous glucocorticosteroids would perhaps provide some explanations. Therefore, the accurate and precise measurement of endogenous corticosteroids in bovine urine can be considered a potentially powerful tool in the identification of cattle that received illegal glucocorticoid treatments.

For this purpose, we employed an HPLC-ESI-MS/MS technique, which was preceded by convenient sample preparation methodology (the hydrolysis and SPE extraction). Sample preparation was generally conducted analogously to our previously published procedure (Pavlovic et al. 2012) with some aspects that were studied in more detail.

\subsection{Enzymatic hydrolysis}

Based on previous research and our own experience, we first studied the necessity of the deconjugation process of eventually present glucuronide/sulphate conjugates. As far as bovine urine is concerned, the greater part of tetrahydro-metabolites are excreted predominantly as glucuronide conjugates, while $\mathrm{F}$ and $\mathrm{E}$ are most prevalent in their free form (Antignac et al. 2002). Arioli et al. 
(2012) showed that, as far as PL is concerned, hydrolysis is not indispensable, as this corticosteroid is present almost exclusively in its free form. Taking all of this into account, we chose to perform our analysis using the most specific enzyme (Escherichia coli $\mathrm{K} 12 \beta$-glucuronidase) to liberate the tetrahydro-corticosteroids. Therefore, the levels reported herein represent the sum of free and glucuronidated forms. This is an important point of clarification, as it can be speculated that alternative methods that hydrolyse both glucuronide and sulphate conjugates may cause an eleyation in final concentrations. To exclude this type of doubt, during preliminary experiments, we performed the simultaneous cleavage of glucuronides and sulphate conjugates by applying Helix pomatia juice as the enzyme source. The concentration did not vary significantly (less $5 \%$ for all compounds), while heterogeneous properties of the Helix pomatia mixture provoked substantial matrix effects, pronounced background noise and a lower $\mathrm{S} / \mathrm{N}$ ratio. We concluded that the sulphatase activity in addition to glucuronidase activity was not essential in this case.

Special attention was dedicated to aTHF as it has been reported that its glucuronides require more extreme conditions to be cleaved (Cuzzola et al. 2014) and because in our previous study it was not found (Pavlovic et al. 2012). Hydrolysis experiments of urine samples were carried out varying the incubation time $(4 \mathrm{~h}, 8 \mathrm{~h}$ and $12 \mathrm{~h})$ and the temperature $\left(37^{\circ} \mathrm{C}, 45^{\circ} \mathrm{C}\right.$ and $\left.55^{\circ} \mathrm{C}\right)$ but once again, this metabolite aTHF was not detected in our bovine samples. The same was noticed for aTHE. Finally, the temperature and duration of hydrolysis were optimised to $40 \mu \mathrm{L}$ of enzyme solution at $55^{\circ} \mathrm{C}$ for $4 \mathrm{~h}$ (Fig. 2). No substantial enhancement in yield of any corticosteroids was observed when any of these parameters was increased.

\subsection{Sample SPE purification}

Sample purification through an Oasis HLB cartridge was designed to quantitatively extract the corticosteroids of interest and minimise interferences present in the urine matrix. The SPE procedure that we applied was similar to that previously reported for human urine (Cuzzola et al. 2009), with necessary adjustments for bovine urine (Pavlovic et al. 2012). A particularly important modification was the employment of just $1 \mathrm{~mL}$ of bovine urine. Greater initial sample volumes, although they provided higher absolute responses, sometimes caused more pronounced background noise and (in a few cases) presented interfering peaks.

\subsection{Optimization of mass spectrometry acquisition and chromatographic separation}

Fragmentation patterns of corticosteroids were studied in ESI (-) mode where pseudo-molecular ion species were present as formic acid adducts at $[\mathrm{M}+\mathrm{HCOO}]^{-}$. After preliminary trials, in full-scan mode from 50 to $500 \mathrm{~m} / \mathrm{z}$, the minimum three product ions with the higher $\mathrm{S} / \mathrm{N}$ ratio for each analyte 
and internal standard were chosen for identification. The diagnostic product ions (among which is the ion for quantification), the relative intensities, and the collision energies (CEs) are reported in Table 1 and Fig. 3. The precise adjustment of CE for each MRM was performed in order to reach the highest sensitivity and specificity for each compound. However, the fragmentation of some analytes that had equal molecular mass (cortisone and PL for example) was careful studied in order to enhance the capabilities of the method, avoiding the common transition. The $\mathrm{m} / \mathrm{z}$-values of the selected parent and daughter ions used for MS detection were generally in agreement with those previously reported by Chiesa et al. (2014). Special consideration was focused on fragmentation of the tetrahydro-metabolites, as there is limited number of publication that deal with the behaviour of their formic acid adducts in an ESI(-) source (Cuzzola et al. 2009). Our MS/MS conditions were tuned to achieve a massspectrometric profile with four characteristic ions, providing the specific product ion ratios that were used for confirmation purposes. The most abundant product ion that corresponds to the cleavage of the side chain and loss of formaldehyde $\left[\mathrm{M}-\mathrm{CH}_{2} \mathrm{O}-\mathrm{H}\right]^{-}$were $\mathrm{m} / \mathrm{z}=333$ and $\mathrm{m} / \mathrm{z}=335$, respectively, for THF and THE, which is in agreement with the recently published paper from Zhai et al. (2015). The selection of the most abundant product ion was the best option in order to optimize the sensitivity and specificity of the tetrahydro-metabolite characterisations. Interestingly, it was not case for $\mathrm{F}$ and $\mathrm{E}$. The quantifiers that were chosen for them are other than the most abundant ions. The reason is simple: the most intense fragments from $\mathrm{F}$ and $\mathrm{E}$ are formed by cleavage of the $\mathrm{C}_{20}-\mathrm{C}_{21}$ bond (ions $\mathrm{m} / \mathrm{z}=329$ and $\mathrm{m} / \mathrm{z}=331$, respectively), and are also present in some interfering co-eluting compounds. The further fragment (319) of THF is most probably formed when $\left[\mathrm{M}-\mathrm{CH}_{2} \mathrm{O}-\mathrm{H}\right]^{-}$loses the methane (16Da) giving $\left[\mathrm{M}-\mathrm{CH}_{2} \mathrm{O}-\mathrm{CH}_{4}-\mathrm{H}\right]^{-}$which is similar to the finding reported for PL (Ferranti et al. 2011; Savu et al. 1996). The ion $\mathrm{m} / \mathrm{z}=301$ is produced when $\mathrm{H}_{2} \mathrm{O}$ subsequently is removed from the steroid moiety (probably via the hydroxyl group from $\mathrm{C}_{11}$ ) leading to formation of the $\left[\mathrm{M}-\mathrm{CH}_{2} \mathrm{O}-\mathrm{CH}_{4}-\mathrm{H}_{2} \mathrm{O}-\mathrm{H}\right]^{-}$ion. These findings are analogues with those that Mitamura et al. (2014) have recently reported describing transitions of different tetrahydrocorticosteroid sulphates. Regarding the THE, complete elimination of the side chain (cleavage of $\mathrm{C}_{17}-\mathrm{C}_{20}$ bond) provided a fragment at $\mathrm{m} / \mathrm{z}=305$, while for the product ion at $m / z=261$ structural assignments seem to be too speculative. The molecular $[M-H]^{-}$ions $(\mathrm{m} / \mathrm{z}=363$ and $\mathrm{m} / \mathrm{z}=365$ ) were identified in second transition, and their appearance was enabled by applying a low collision energy. Turpeinen et al. (2006), with methanol and water as the mobile phase, used those deprotonated molecular ions as a parent in the LC-MS/MS determination of tetrahydro-corticosteroids. Those authors also obtained a slightly different mass spectrum for two tetrahydro-isomers, which in our case was not possible. 
Attempts were made to acquire different fragmentation patterns and thus to distinguish aTHF from THF and aTHE from THE, but unfortunately these were without success. Therefore, the chromatographic column and gradient elution programme was carefully optimised until it permitted the complete separation of the isomers (Fig. 3). For this purpose, we used a new Raptor Biphenyl Column that employs a phenyl-hexyl stationary phase, with an innovative biphenyl ligand, which is the first time it has been used in corticosteroid separation. The unique composition of biphenyl groups in sterically favourable positions improves the interactions with steroid fused-ring moieties, resulting in baseline separation of very structurally similar corticosteroids, including two pairs of diastereoisomers. The separation of aTHF and THF was relatively easy to achieve, first of all because of the increased polarity due to presence of three hydroxyl groups. The $\mathrm{OH}$-group from $\mathrm{C}_{1}$ seems especially important as it interacts in a particular manner with the rest of the steroid moiety, which subsequently provokes distinct distribution of aTHF and THE between the mobile and stationary phases. Secondly, aTHF is a conformer where the $\mathrm{A} / \mathrm{B}$ rings are joined though two equatorial-type bonds (trans-decalin type) whereas an axial-equatorial union gives the cis-decalin form. The separation of THE and its allo-isomer is an actual problem, not easily overcome and this is related to the $\mathrm{C}_{11}$ keto function. That is why THE and aTHE frequently are determined in human clinical practice as a combination. More often, only THE is considered as the reduced metabolite of $\mathrm{E}$ while the level of aTHE is ignored (Główka et al. 2010). The reason for such simplification may be the much lower level of aTHE in comparison to THE in human urine (Vierhapper, 2000). However, with our chromatographic conditions, baseline separation of those isomers was fully accomplished because, analogously to aTHF/THF, the biphenyl column is capable of chromatographically distinguish A/B ring conformers.

\subsection{Method validation}

Specificity and selectivity were evaluated as described in the materials and methods section, applying the Commission Decision 2002/657/CE. Blank samples $(n=10)$ were analysed and did not show any interference (signals, peaks, ion traces) in the region of interest, where the target analytes were expected to be. The relative retention time of the analytes corresponded to that of the standards, with a tolerance of $\pm 2.5 \%$. Relative intensities of the product ions, expressed as a percentage of the intensity of the most intense ion, corresponded to those of the reference analyte. The relative intensities of the detected ions were within the permitted tolerances: the ion ratio of the product ion with relative intensity greater than $50 \%$ did not exceed the tolerance of $20 \%$. Nonetheless, if relative ion intensity was in ranges either $20-50 \%$ or $20-10 \%$ the deviance in intensity was not allowed to be higher than $25 \%$ and $30 \%$, respectively. 
Seven concentration levels with three replicates each were used to build the regression line using the least square method. The calibration curve equations were used to calculate unknown concentrations in real urine samples of bovines enrolled in the experimental study. Regression coefficients of the curves showed very good linearity for all compounds (Table 2). The LLOQ values (Table 2) indicated that this method could be used for confirmation purposes, as recommended maximal residual levels allowed in urine are set at $2 \mathrm{ng} \mathrm{mL}^{-1}$ for DX ( CRL Guidance Paper, 2007) and $5 \mathrm{ng} \mathrm{mL}^{-1}$ for PL (PNR).

Precision, defined as the closeness of agreement between independent test results obtained under the stipulated conditions, is herein expressed as the repeatability. The intra-repeatability was satisfactory, with the relative standard deviation (RSD) ranging from $6 \%$ to $11 \%$, whereas analysis of inter-day repeatability resulted in slightly higher variability (up to $20 \%$ ). Instrumental precision was between $8 \%$ and $17 \%$ for all analytes. These results show good repeatability, indicating a stable instrumental response as far as the performance of the HPLC-ESI-MS/MS system is concerned.

The overall recovery of the method, conducted on real urine samples with predetermined corticosteroid concentrations attained by adding known amounts of standards, ranged between 75 and 114\% as presented in Table 3. The two main reduced steroids (THF and THE) had the lowest recovery rates, almost certainly because of it particular structure and conformation. Those steroids belong to the $5 \alpha$-cholestan series with the cis positioning between $\mathrm{A} / \mathrm{B}$ ring causing that steroidal structure is not linear as for $\mathrm{F}$ and $\mathrm{E}$ e.g., but slightly bended. This reduction in overall molecule surface could, in some extend, compromise efficient retention on hydrophilic-lipophilic balanced polymers from SPE Oasis.

Assessment of matrix effects is mandatory in the validation of a quantitative assay using HPLC-ESI-MS/MS in biological samples, since endogenous impurities can affect the ionization process and may reduce or increase the efficiency of formation of the desired analyte ions. At the same time, the SPE purification step can be indirectly validated. Our study documented the absence of a significant matrix effect, with aTHF being the analyte that had the most evident ion suppression. This is obviously affected by the presence of electrolytes and ionisable co-eluting species, as this steroid is first to be eluted. Nevertheless, as other validation data, such as sensitivity and linearity, were acceptable and indicated good performance of the developed method, this was not considered a drawback for accurate determination.

3.5 The impact of dexamethasone and prednisolone on endogenous corticosteroids production: real sample analysis 
An important objective of this study was to apply the developed method to real urine samples from veal calves enrolled in an experimental treatment consisting of long-term PL and DX administration. The first group that we considered was the control group that did not receive any therapy (Table 4). It is worth noting that PL was detected in urine of control animals: median yalues were 0.72 and $0.74 \mathrm{ng} \mathrm{mL}^{-1}$ at the second and third time points, respectively. This supports the theory that PL can be produced as an endogenous substance, at least for healthy Friesian veal calves. The concentrations found are extremely low and, in some of our samples, barely detectable. Up to now, it has been demonstrated that PL could be generated in food-producing cattle by physiological metabolic processes, possibly under extremely stressful conditions, such as transport and slaughter, or by faecal contamination, as is supported by a few recent studies (Arioli et al. 2010; Ferranti et al. 2011; Pompa et al. 2011). On the basis of these results and the opinion of the European Reference Laboratory, the Italian Ministry of Health has recently enacted a new disposition: a bovine urine sample is considered non-compliant for PL only when its concentration exceeds 5.0 ppb (Circular of Ministry of Health, 2012). Recently, evidence has been provided that veal calves, besides endogenous PL production, revealed remarkable $\mathrm{F}$ and $\mathrm{E}$ urine concentrations as a response to extremely stressful conditions ( Ferranti et al, 2013). The presumption was made that PL might be formed by the dehydrogenation of $F$ due to the enterohepatic circulation process. Although the determination of the PL biosynthetic route was beyond the aim of this research, and bearing in mind that our experiment was designed to avoid any type of stress, it can be noticed that in the control group PL appeared along with higher F and $\mathrm{E}$ concentrations: on day 15, those levels were 4.07, 9.89 and $0.72 \mathrm{ng} \mathrm{mL}^{-1}$ for E, F and PL respectively. PN residue was found only in one urine sample without any correlation to the highest levels of PL, F or $\mathrm{E}$ and it is probably due to some individual metabolic state of the animal at this time point.

The data obtained from the control group provides preliminary information regarding the physiological leyels of A-ring reduced $\mathrm{F}$ and $\mathrm{E}$ in non-treated, healthy veal calves, which has not been reported in the literature up to now. The measured values exhibited a high intergroup variation having THF and THF values ranging from 7.54-49.22 and $1.80-22.38 \mathrm{ng} \mathrm{mL}^{-1}$, respectively. In general, no official threshold has been established for natural hormone concentrations in bovine urine, mainly due to the fact that concentrations of naturally occurring hormones are highly variable and depend on the type of animal product, breed, gender, age, disease, medication and physiological condition (Antignac et al. 2002; Angeletti et al. 2006; Pleadin et al. 2011). In our research, aTHF and aTHE were below the detection limit, unlike results obtained for human urine (Cuzzola et al. 2014). These findings imply that for the natural corticosteroids in bovine, $5 \beta$-reduction predominates over the $5 \alpha$-reductase activity. The 
virtual absence of $5 \alpha$-reduction of $F$ and $E$ is represented visually in the MRM chromatograms illustrated in Fig. 3. This indicates that there are substantial differences between human and bovine production of $\mathrm{F}$ and $\mathrm{E}$ A ring metabolites.

Data obtained from veal calves treated with PL revealed the low concentrations of this glucocorticoid in most, but not all, urine samples collected in the course of treatment (Table 5), which confirms previous findings (Cannizzo et al. 2011). Despite the significantly 20-times higher dose administered with respect to DX, it is metabolised much faster and apparently, the depletion pattern does not depend on the administered dose. Three days after treatment suspension, PL was still detected in half of the samples. In the middle of treatment a very low concentration of PN was found (day 25), as it is formed as a metabolite from the interconversion of PL.

PL significantly interfered with the production of $\mathrm{F}$ and $\mathrm{E}$, leading to complete depletion of both. Nebbia et al. (2014) also observed a decrease in F and Elevels in finishing bulls and cows after therapeutic treatment with PL acetate. This is to some extent in contrast with our preliminary study (Pavlovic et al. 2013) where no differences were found in the F and $\mathrm{E}$ excretion time course during PL treatment in male cattle. The plausible explanation for this discrepancy is that those experimental subjects differed in age and consequently in metabolism (veal calves are not yet ruminant). Although in both experiments the same dosage (15 mg/day for 30 consecutive days) of PL was administered, in veal calves it resulted in approximately double the dose relative to the animals' weight, which averaged 60 $\mathrm{kg}$ for veal calves vs. $120 \mathrm{~kg}$ for beef cattle. Furthermore, considerable impact could be attributed to a different sampling schedule, since the last time point in our previous experiment was at slaughter, which intensified the extremely stressful situation. As was mentioned above, heavy stress conditions apparently favour endogenous PL production that is usually accompanied by an increase in urinary concentrations of F and E (Bertocchi et al. 2013; Ferranti et al. 2013), while exogenous administration of PL is likely to reduce the production of these main endogenous glucocorticoids. Our results confirm this hypothesis and are enriched with monitoring of the levels of $\mathrm{F}$ and $\mathrm{E}$ A-ring reduced metabolites.

As far as THF is concerned, its concentration significantly and gradually decreased during PL treatment, and remained low three days after the drug was discontinued. The THE levels showed a tendency to decline, but without statistical significance. Consequently, the THF/THE ratio remained unaffected. This indicated that it was better to consider the absolute values of THF and THE instead of their molar ratio. For this purpose, reference or threshold levels need to be introduced. So far, the metabolic fate of exogenously administered PL is relatively unknown, although some very important studies have been conducted recently (Vincenti et al. 2012; Ferranti et al. 2013; Nebbia et al. 2014). 
The evident decrease in A-ring reduced $\mathrm{F}$ and $\mathrm{E}$ metabolites during the course of PL treatment may represent a new approach that would discriminate between exogenous and endogenous PL origin.

Quantitative data from the urine samples in animals treated with DX are reported in Table 6. This drug was not identified at the first check-up (day 15), but a substantial amount was found in all samples collected at day 25. The results obtained in our experiments could be, only in limited extent, compared to the ones observed in previous studies, mostly because of the striking differences in both dosage and duration of DX administration. The elimination kinetics were in line with previously published data regarding the grow-promotion protocol (Vincenti, et al. 2009). The values obtained are comparable with that obtained in beef cattle (Cannizzo et al. 2011) especially when it comes to the amount of drug dosed per $\mathrm{kg}$ of animal body weight: $0.4 \mathrm{mg} /$ day for veal calves vs. $0.7 \mathrm{mg} /$ day for beef. The main differences were observed in the samples taken after suspension of the treatment: in previous work no detectable residues were found six days after drug withdrawal, whereas in this study, approximatively the same quantity detected on day 25 was also measurable three days after the end of treatment (day 40). This might be due to the slightly different experimental design, such as the cattle breeds (Friesian vs. Charolaise) and animal age (veal calves vs. beef). However, the sampling schedule after the end of the treatment (sixth vs. third day) has to be taken as the more plausible reason for those findings. Apart from the fact that it is well known that DX reduces F levels (Ljung et al. 1996; Vincenti et al. 2009; Ferranti et a 2011; Ferranti et al. 2013), the withstanding result from this group is that the low dosage of DX given daily p.o. was capable of completely depleting E and F. This method of drug administration could accomplish circulating steady state concentrations of DX capable of influencing the production of endogenous $F$ much more than the higher intermittent intramuscular dose applied by Capolongo et al. (2007). The same studies also indicated the urinary free $6 \beta-\mathrm{F} / \mathrm{F}$ as new promising screening test for detection of long-term DX illicit administration in cattle, but very resent data suggest that it could not be a reliable biomarker of illicit DX treatment as presence of $6 \beta-F$ was not always registered (Famele et al. 2015).

No detectable residues were found as far as THF is concerned, at the same sampling points as for $\mathrm{F}$ and $\mathrm{E}$ whereas THE expressed an interesting behaviour: after complete depletion at day 25, it appeared again in urine three days after the withdrawal of DX. This indicates that low dose administration of DX reversibly influences the metabolic pathway, which involves the two-step enzymatic transformation of $\mathrm{E}$ to THE by $5 \beta$-reductase, followed by the reduction of the 3-keto group catalyzed by $3 \alpha$-oxoreductase (Draper $\&$ Stewart 2005). The short withdrawal period was enough to 
restore enzymatic activity responsible for $\mathrm{E}$ to THE transformation, while it was not the case for the corresponding F to THF conversion. In addition, appearance of THE after DX removal is attributable to prompt reestablishment of $11 \beta$-HSDII activity, as well. This finding qualifies THF and THE as promising biomarkers that could be useful to the evaluation of DX abuse in cattle. Also, it remains to be established whether the complete disappearance of four natural corticosteroids in the course of DX treatment is associated with up-regulation of both 11ß-HSDs in adrenal tissue (Cannizzo et al. 2013).

\section{CONCLUSIONS}

The development of analytical procedures based on the HPLC-ESI-MS/MS technique was indispensable to carry out investigations regarding the effects of DX and PL on the metabolism of the main endogenous glucocorticosteroids. The method validation requirements were completely fulfilled: the method was precise, accurate, sensitive and reliable for the above mentioned scope. The presented data provide an indication of the utility of the method for the assessment of 11-hydroxysteroid dehydrogenases and $5 \beta$-reductase activity associated with DX or PL treatment. Further studies are needed to understand the mechanisms of DX and PL action on F and E. In particular, it would be interesting to study more in-depth the origin of the specific behaviour of the corresponding tetrahydrometabolites during DX and PL administration. Furthermore, it remains to be clarified whether results observed herein might represent a promising tool for the detection of illicit treatment of bovine with DX or PL.

\section{Acknowledgments}

This work was partially funded by the Ministero delle Politiche Agricole Alimentari e Forestali SAFORISK project. 


\section{REFERENCES}

Angeletti R, Contiero L, Gallina G, Montesissa C, 2006. The urinary ratio of testosterone to epitestosterone: a good marker of illegal treatment also in cattle? Vet Res Comm. 30(1):127-131.

Antignac JP, Le Bizec B, Monteau F, André F. 2002. Study of natural and artificial corticosteroid phase II metabolites in bovine urine using HPLC-MS/MS. Steroids. 67:873-882.

Arioli F, Casati A, Fidani M, Silvestri, M, Pompa, G, 2012. Prednisolone and prednisone neoformation in bovine urine after sampling. Animal. 6:1023-1029.

Arioli F, Fidani M, Casati A, Fracchiolla ML, Pompa G. 2010. Investigation on possible transformations of cortisol, cortisone and cortisol glucuronide in bovine faeeal matter using liquid chromatography-mass spectrometry. Steroids. 75:350-354.

Bertocchi L, Dusi G, Ghidelli V, Hathaway T, Nassuato C, Casati A, Fidani M, Pompa G, Arioli, F. 2013. Investigation of the origin of prednisolone in urine and adrenal glands of cows. Food Addit Contam A. 30:1055-1062.

Cannizzo FT, Capra P, Divari S, Ciccotelli V, Biolatti B, Vincenti M. 2011. Effects of low-dose dexamethasone and prednisolone long-term administration in beef calf: Chemical and morphological investigation. Anal Chim Acta. $700(1-2): 95-104$.

Cannizzo FT, Crispo M, Divari S, Starvaggi L, Cucuzza M, Biolatti B. 2013. Corticosteroid hormone receptors and prereceptors on hypothalamus-pituitary-adrenal axis of veal calves. LXVII Convegno Nazionale S.ISVet, Società Italiana delle Scienze Veterinarie. Book of abstracts 77.

Capolongo F, Tapparo M, Merlanti R, Ravarotto L, Tealdo E, Gallina G, Montesissa C, Dacasto M. 2007. Illicit treatments in cattle and urinary 6beta-hydroxycortisol/cortisol ratio. Anal Chim Acta. 586: $228-232$.

Chiesa L, Nobile M, Panseri S, Sgoifo Rossi CA, Pavlovic R, Arioli F. 2014. Detection of boldenone, its conjugates and androstadienedione, as well as five corticosteroids in bovine bile through a unique immunoaffinity column clean-up and two validated liquid chromatography-tandem mass spectrometry analyses. Anal Chim Acta. 852: 137-145.

Circular of Ministry of Health, Department of Public and Veterinary Health about the opinion of the Consiglio Superiore di Sanità. Sezione IV, of 22 May 2012. 
Courtney R, Stewart PM, Toh M, Ndongo MN, Calle RA, Hirshberg B. 2008. Modulation of 11 $\beta$ Hydroxysteroid Dehydrogenase (11ßHSD) Activity Biomarkers and Pharmacokinetics of PF00915275, a Selective 11ßHSD1 Inhibitor, Clin Endocrinol Metab. 93:550-556.

CRL Guidance Paper. 2007. CRL Guidance paper (7 December 2007). CRLs view on state of the art analytical methods for national residue control plans. $8 \mathrm{pp}$. Available from: http://www.bvl.bund.de/SharedDocs/Downloads/09_Untersuchungen/EURL_Empfehlungen_Konzentr ationsauswahl_Methodenvalierungen.pdf?_blob=publicationFile

Cuzzola A, Mazzini F, Petri A. 2014. A comprehensive study for the validation of a LC-MS/MS method for the determination of free and total forms of urinary cortisol and its metabolites. J Pharm Biomed Anal. 94:203-209.

Cuzzola A, Petri A, Mazzini F, Salvadori P. 2009. Application of hyphenated mass spectrometry techniques for the analysis of urinary free glucocorticoids. Rapid Commun Mass Spectrom. 23:29752982.

Divari S, Cannizzo FT, Uslenghi F, Pregel P, Mûlasso C, Spada F, De Maria R, Biolatti B. 2011. Corticosteroid hormone receptors and prereceptors as new biomarkers of the illegal use of glucocorticoids in meat production. J Agric Food Chem. 59 (5):2120-2125.

Draper N, Stewart PM. 2005. 11 beta-Hydroxysteroid dehydrogenase and the pre-receptor regulation of corticosteroid hormone action. JEndocrinol. 186:251-271.

European Commission. 2002. Decision No. 657/2002. Off J Eur Comm Legis. 221:8-36.

Famele M, Ferranti C, Palleschi L, Abenavoli C, Fidente R, Pezzolato M, Botta M, Bozzetta E, Draisci R. 2015. Quantification of natural and synthetic glucocorticoids in calf urine following different growth-promoting prednisolone treatments. Steroids. 104:196-202.

Ferranti C, delli Quadri F, Palleschi L, Marchiafava C, Pezzolati M, Bozzeta E, Carmelli M, Draisi R. 2011. Studies on the presence of natural and synthetic corticosteroids in bovine urine. Steroids. 76(6):616-625.

Ferranti C, Famele M, Palleschi L, Bozzetta E, Pezzolato M, Draisci R. 2013. Excretion profile of corticosteroids in bovine urine compared with tissue residues after therapeutic and growth-promoting administration of dexamethasone. Steroids. 78(9):803-812. 
Główka F, Kosicka K, Karazniewicz-Łada M. 2010. HPLC method for determination of fluorescence derivatives of cortisol, cortisone and their tetrahydro- and allo-tetrahydro-metabolites in biological fluids. J Chromatogr B. 878:283-289.

Ljung T, Andersson B, Bengtsson B, Bjorntorp P, Marin P. 1996. Inhibition of cortisol secretion by dexamethasone in relation to body fat distribution: a dose-response study. Obes Res. 4:277-282.

Matuszewski BK, Constanzer ML, Chavez-Eng CM. 2003. Strategies for the assessment of matrix effect in quantitative bioanalytical methods based on HPLC-MS/MS. Anal Chem. 75:3019-3030.

Mazzarino M, Rossi F, Giacomelli L, Botre'. F, 2006. Effect of the systemic versus inhalatory administration of synthetic glucocorticoids on the urinary steroid profile as studied by gas chromatography-mass spectrometry. Anal Chim. Acta 559:30-36.

Mitamura K, Satoh R, Kamibayashi M, Sato K, Iida T, Ikegawa S. 2014. Simultaneous determination of 18 tetrahydrocorticosteroid sulfates in human urine by liquid chromatography/electrospray ionization-tandem mass spectrometry. Steroids 85:18-29.

Möstl E, Messmann S, Bagu E, Robia C, Palme R. 1999. Measurement of glucocorticoid metabolite concentrations in faeces of domestic livestock, Zentralbl Veterinarmed A. 46(10):621-631.

Nebbia C, Capra P, Leporati M, Girolami F, Barbarino G, Gatto S, Vincenti M. 2014. Profile of the urinary excretion of prednisolone and its metabolites in finishing bulls and cows treated with a therapeutic schedule. BMC Vet Res. 10: 237

Pavlovic R, Cannizzo FT, Panseri S, Biolatti B, Trutic N, Biondi PA, Chiesa L. 2013. Tetrahydrometabolites of cortisol and cortisone in bovine urine evaluated by HPLC-ESI-mass spectrometry. J Steroid Biochem MolBiol. 135: 30-35.

Pavlovic R, Chiesa LM , Soncin S, Panseri S, Cannizzo FT, Biolatti B, Biondi PA. 2012. Determination of cortisol, cortisone, prednisolone and prednisone in bovine urine by liquid chromatography-electrospray ionisation single quadrupole mass spectrometry. J Liq Chromatogr RT. $35(3): 444-457$.

Pegolo S, Di Camillo B, Montesissa C, Cannizzo FT Biolatti B, Bargelloni L. 2015. Toxicogenomic markers for corticosteroid treatment in beef cattle: Integrated analysis of transcriptomic data. Food Chem Toxicol. 77: 1-11 
Pleadin J, Terzić S, Perši N, Vulić A. 2011. Evaluation of steroid hormones anabolic use in cattle in Croatia, Biotechnol Anim Husb. 7(2):147-158.

Pompa G, Arioli F, Cassati A, Fidani M, Bertocchi L, Dusi G. 2011. Investigation of the origin of prednisolone in cow urine. Steroids. 76:104-110.

Pirro V, Girolami F, Spalenza V, Gardini G, Badino P, Nebbia C. 2015 Set-up of a multivariate approach based on serum biomarkers as an alternative strategy for the screening evaluation of the potential abuse of growth promoters in veal calves. Food Addit Contam Part A. 32(5):702-711.

Quinkler M, Stewart PM. 2003. Hypertension and the cortisol-cortisone shuttle. J Clin Endocrinol Metab. 88:2384-2392.

Raffaelli A, Saba A, Vignali E, Marcocci C, Salvadori P. 2006. Direct determination of the ratio of tetrahydrocortisol + allo-tetrahydrocortisol to tetrahydrocortisone in urine by LC-MS-MS. J Chromatogr B. 830: 278-285.

Savu SR, Silvestro L, Haag A, Sörgel F. 1996. A confirmatory HPLC-MS/MS method for ten synthetic corticosteroids in bovine urines. J Mass Spectrom. 31:1651-1363.

Tomlinson JW, Sherlock M, Hughes B, Hughes SV, Kilvington F, Barlett W, Courtney R, Rejto P, Carley W, Stewart PM. 2007. Inhibition of 11 beta-hydroxysteroid dehydrogenase type 1 activity in vivo limits glucocorticoid exposure to human adipose tissue and decreases lipolysis. J Clin Endocrinol Metab. 92:857-864.

Turpeinen U, Markkanen H, Sane T, Hämäläinen E. 2006. Determination of free tetrahydrocortisol and tetrahydrocortisone ratio in urine by liquid chromatography-tandem mass spectrometry. Scand J Clin Lab Invest. 66(2):147-159.

US Department of Health and Human Services, Food and Drug Administration, Center for Drug Evaluation and Research (CDER), Center for Veterinary Medicine (CVM), May 2001. BP. Guidance for Industry Bioanalytical methods validation [online]. Available from URL http://www.fda.gov/downloads/Drugs/Guidances/ucm070107.pdf

Vascellari M, Capello K, Stefani A, Biancotto G, Moro L, Stella R, Pozza G, Mutinelli F. 2012. Evaluation of thymus morphology and serum cortisol concentration as indirect biomarkers to detect low-dose dexamethasone illegal treatment in beef cattle. BMC Vet Res. 8 (1):129. 
Vierhapper H. 2000. The stress of being a doctor: steroid excretion rates in internal medicine residents on and off duty. Am J Med. 109:492-494.

Vincenti M, Girolami F, Capra P, Pazzi M, Carletti M, Gardini G, Nebbia C. 2009. Dexamethasone Urinary Excretion in Cattle. J Agric Food Chem. 57 (4):1299-1306.

Vincenti M, Leporati M, Capra P, Gatto S, Attucci A, Barbarino G, Nebbia, C. 2012. A field survey on the presence of prednisolone and prednisone in urine samples from untreated cows. Food Addit Contam Part A. 29 (12):1893-1900.

Vincenti M, Leporati M, Capra P, Gatto S, Attucci A, Barbarino G, Nebbia C. 2012. A field survey on the presence of prednisolone and prednisone in urine samples from untreated cows. Food Addit Contam Part A. 29 (12):1893-1900.

White PC In: Becker KL, editor 2001. Principles and practice of endocrinology and metabolism. Philadelphia: Lippincott Williams \& Wilkins; 704-719.

Zhai X, Chen F, Zhu C, Lu Y, 2015. A simple LC-MS/MS method for the determination of cortisol cortisone and tetrahydro-metabolites in human urine: Assay development, validation and application in depression patients. J Pharm Biomed Anal. 107:450-455. 


\section{Figure captions}

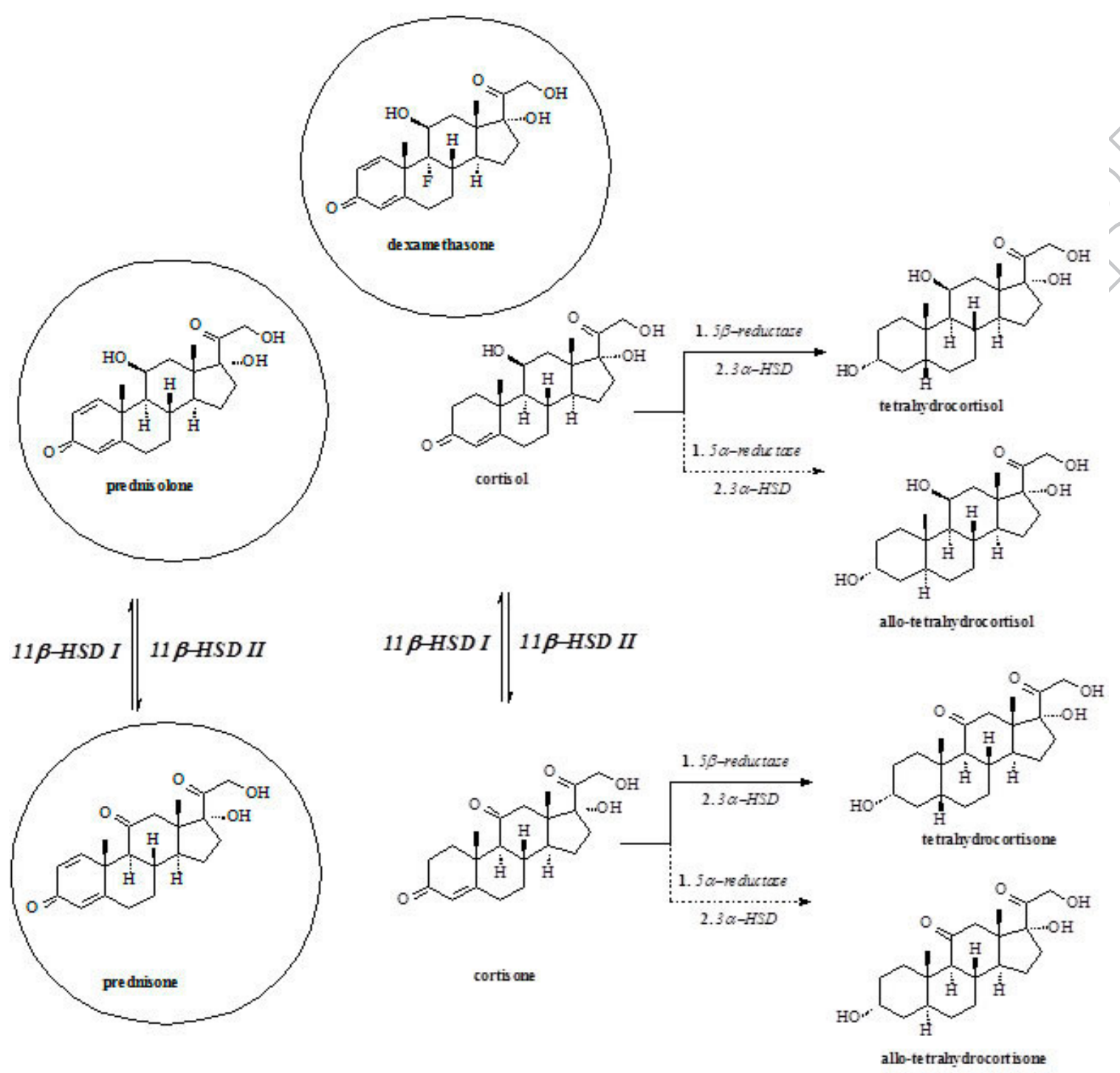

Fig. 1. Interconversion of cortisol/cortisone by $11 \beta$-hydroxysteroid dehydrogenases (11ß-HSDs) and formation of their main A ring reduced metabolites: tetrahydrocortisol and tetrahydrocortisone. Dashed arrows denote the probable metabolic route that would lead to corresponding diastereoisomers allotetrahydrocortisol and allo-tetrahydrocortisone formation. The structures of syntactic glucocorticosteroids are presented as well. 


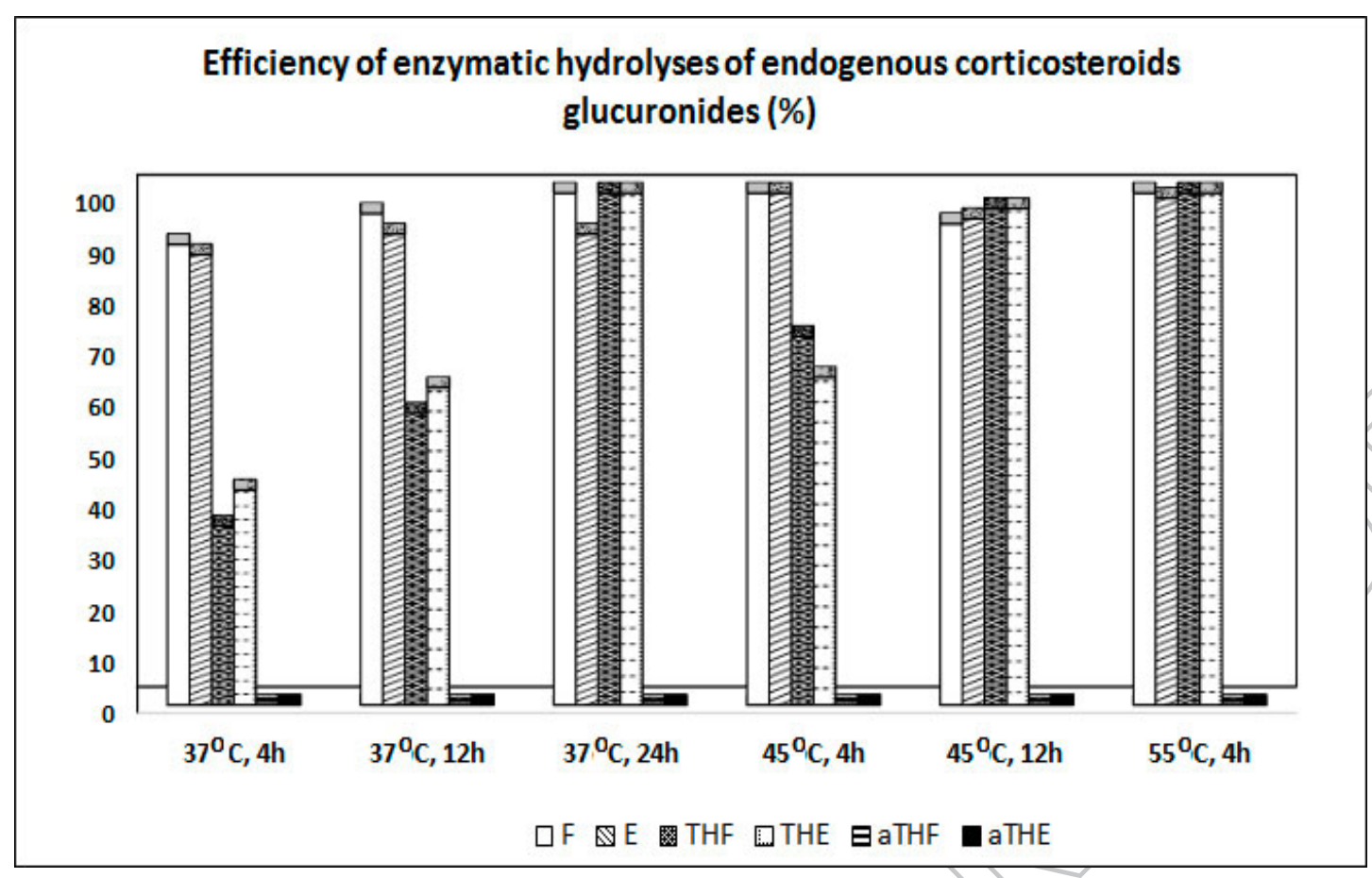

Fig. 2. Influence of temperature and incubation time on the extent of enzymatic hydrolysis of conjugated corticosteroids in $1 \mathrm{~mL}$ of calves' urine at $\mathrm{pH} 6.2$ with $40 \mu \mathrm{L} \beta$-glucuronidase from Escherichia coli K 12 (EC 3.2.1.31). The highest yield of hydrolysis for each compound is fixed as $100 \%$ and all other values are given as a $\%$ of this yield. 

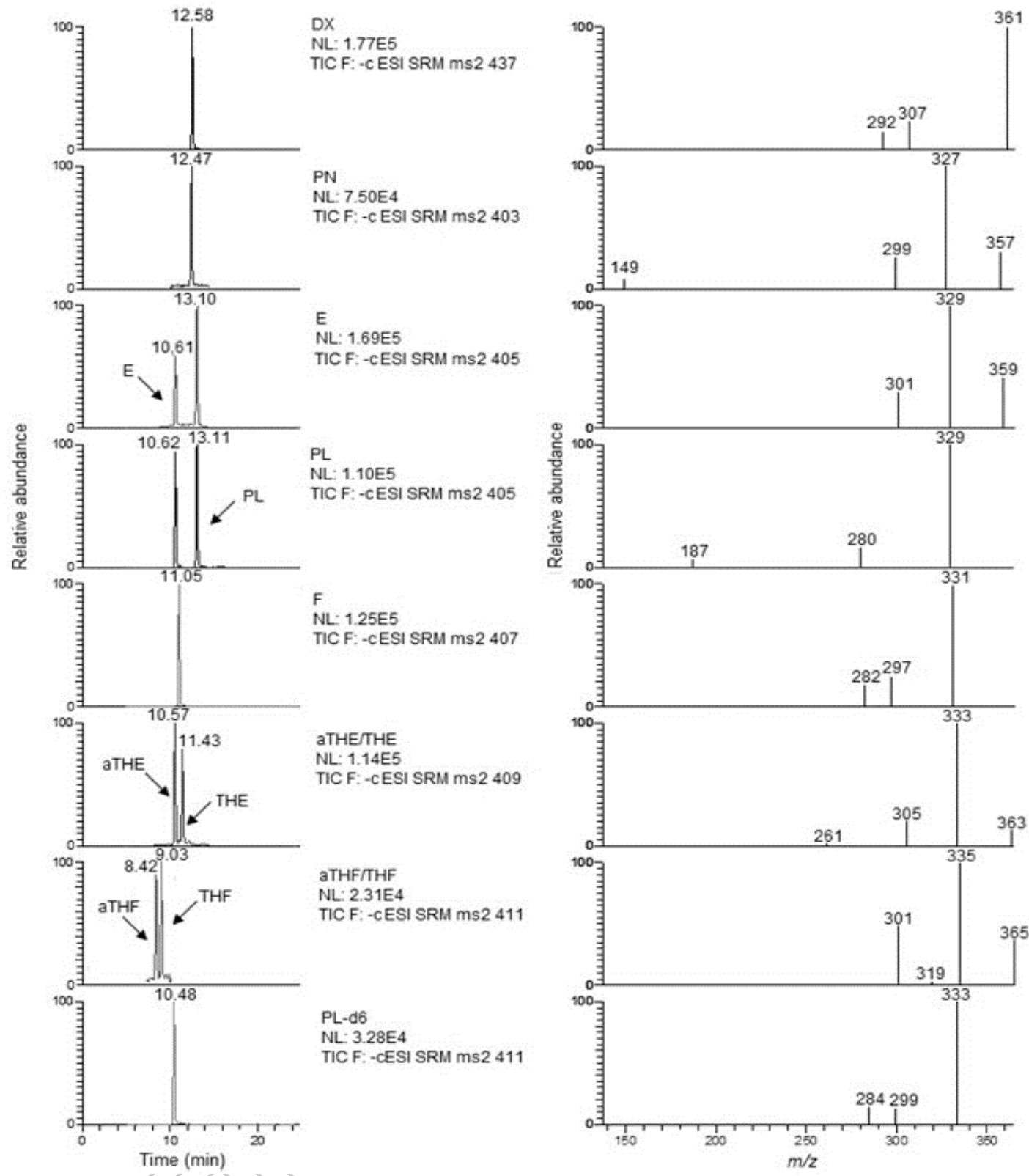

Fig. 3. HPLC-ESI-MS/MS chromatograms and related MS spectra of the studied corticosteroids in a blank urine sample spiked at the concentration of $5 \mathrm{ng} \mathrm{mL}^{-1}$. 
Table 1. Precursor ions and specific diagnostic ions with tube values and collision energies (CE) of the targeted corticosteroids. Ions for quantification are in bold.

\begin{tabular}{|c|c|c|c|}
\hline Analyte & $\begin{array}{l}\text { Precursor } \\
\text { ion }(\mathrm{m} / \mathrm{z})\end{array}$ & Product ions $(\mathrm{m} / \mathrm{z})$ & Tube lens \\
\hline $\mathrm{F}$ & 407 & $282_{(37), 297_{(33),}, 331_{(20)}^{a}}$ & 74 \\
\hline$E$ & 405 & $137_{(45),}, 301_{(22),} 329_{(19)}^{\mathrm{a}} 359_{(13)}$ & 72 \\
\hline PL & 405 & $187_{(30)}, 280_{(35)}, 329^{\mathrm{a}}{ }_{(19)}$ & 71 \\
\hline PN & 403 & $149_{(45)}, 299_{(21)}, 327_{(19)}^{\mathrm{a}} 357_{(12)}$ & 52 \\
\hline aTHE /THE & 409 & $261_{(37)}, 305_{(25)}, 333_{(20)}, 363_{(15)}$ & 77 \\
\hline aTHF / THF & 411 & $301_{(37)}, 319_{(29)}, 335_{(21)}, 365_{(15)}$ & 75 \\
\hline DX & 437 & $307_{(33)}, 361_{(20), 391_{(14)}}^{\mathrm{a}}$ & 81 \\
\hline PL-d6 & 411 & $284_{(37),} 299_{(32),} 333^{\mathrm{a}}{ }_{(19)}$ & 77 \\
\hline
\end{tabular}

${ }^{\mathrm{a}}$ Most abundant production 
Table 2. Validation data summary: linearity, LLOQ and repeatability

\begin{tabular}{|c|c|c|c|c|c|c|}
\hline \multirow[b]{2}{*}{ Analyte } & \multirow[b]{2}{*}{ Calibration curve $(n=3)$} & \multirow[b]{2}{*}{$\mathbf{R}^{2}$} & \multirow[b]{2}{*}{ LLOQ } & \multirow{2}{*}{$\begin{array}{l}\text { Spiked } \\
\text { level } \\
\left(\mathrm{ngmL}^{-1}\right)\end{array}$} & \multicolumn{2}{|c|}{ Repeatability } \\
\hline & & & & & $\begin{array}{l}\text { intra-day } \\
\text { (RSD; } \\
(n=6) \\
\end{array}$ & $\begin{array}{l}\text { inter-day } \\
\text { (RSD; } \\
(n=6)\end{array}$ \\
\hline \multirow{2}{*}{$\mathrm{F}$} & \multirow{2}{*}{$\begin{array}{l}Y=0.509( \pm 0.011) X- \\
0.326( \pm 0.247)\end{array}$} & \multirow{2}{*}{0.9905} & \multirow{2}{*}{0.5} & 2.5 & 7 & 13 \\
\hline & & & & 10 & 5 & 17 \\
\hline \multirow{2}{*}{$E$} & \multirow{2}{*}{$\begin{array}{l}Y=0.179( \pm 0.002) X- \\
0.080( \pm 0.047)\end{array}$} & \multirow{2}{*}{0.9971} & \multirow{2}{*}{0.5} & 2.5 & 8 & 12 \\
\hline & & & & 10 & 10 & \\
\hline \multirow{2}{*}{$\mathrm{PL}$} & \multirow{2}{*}{$\begin{array}{l}Y=0.082( \pm 0.001) X- \\
0.060( \pm 0.022)\end{array}$} & \multirow{2}{*}{0.9972} & \multirow{2}{*}{0.5} & 2.5 & & 17 \\
\hline & & & & 10 & & 14 \\
\hline \multirow{2}{*}{ PN } & $Y=0.286( \pm 0.004) X$ & \multirow{2}{*}{0.9968} & \multirow{2}{*}{0.5} & 2.5 & 10 & 17 \\
\hline & $0.258(( \pm 0.080)$ & & & & & 18 \\
\hline \multirow{2}{*}{ aTHF } & $Y=0.074( \pm 0.001) X-$ & \multirow{2}{*}{0.9957} & & & 7 & 20 \\
\hline & $0.041( \pm 0.022)$ & & & & 8 & 18 \\
\hline \multirow{2}{*}{ THF } & \multirow{2}{*}{$\begin{array}{l}Y=0.090( \pm 0.001) X- \\
0.065( \pm 0.029)\end{array}$} & \multirow{2}{*}{0.9944} & \multirow{4}{*}{0.5} & & 6 & 12 \\
\hline & & & & 10 & 5 & 19 \\
\hline \multirow{2}{*}{ aTHE } & \multirow{2}{*}{$\begin{array}{l}Y=0.484( \pm 0.007) X- \\
0.319( \pm 0.153)\end{array}$} & \multirow{2}{*}{0.9960} & & 2.5 & 5 & 12 \\
\hline & & & & 10 & 9 & 14 \\
\hline \multirow{2}{*}{ THE } & \multirow{2}{*}{$\begin{array}{l}Y=0.405( \pm 0.004) \\
0.206( \pm 0.089)\end{array}$} & \multirow{2}{*}{0.9980} & \multirow{2}{*}{0.5} & 2.5 & 9 & 16 \\
\hline & & & & 10 & 10 & 16 \\
\hline \multirow{2}{*}{ DX } & $Y=0.632( \pm 0.009$ & \multirow{2}{*}{0.9963} & 0.5 & 2.5 & 7 & 12 \\
\hline & $0.598( \pm 0.191)$ & & 0.3 & 10 & 11 & 13 \\
\hline
\end{tabular}


Table 3. Recovery data for natural and synthetic corticosteroids enrolled in study

\begin{tabular}{|c|c|c|c|c|}
\hline Analyte & Urine (ng mL ${ }^{-1}$ ) & Spiked (ng mL $L^{-1}$ ) & $\begin{array}{l}\text { Urine + Spike } \\
\left(\mathrm{ng} \mathrm{mL}^{-1}\right)\end{array}$ & Recovery (\%) \\
\hline \multirow{2}{*}{$\mathrm{F}$} & \multirow{2}{*}{1.4} & 2.5 & 2.4 & 114 \\
\hline & & 10 & 9.8 & 110 \\
\hline \multirow{2}{*}{$\mathrm{E}$} & \multirow{2}{*}{2.3} & 2.5 & 4.3 & 111 \\
\hline & & 10 & 12.4 & 116 \\
\hline \multirow{2}{*}{$\mathrm{PL}$} & \multirow{2}{*}{ ND } & 2.5 & 2.8 & 112 \\
\hline & & 10 & 11 & 110 \\
\hline \multirow{2}{*}{ PN } & \multirow{2}{*}{ ND } & 2.5 & 2.33 & \\
\hline & & 10 & 8.9 & 89 \\
\hline \multirow{2}{*}{ aTHF } & \multirow{2}{*}{ ND } & 2.5 & 2.4 & 75 \\
\hline & & 10 & 8.8 & 88 \\
\hline \multirow{2}{*}{ THF } & \multirow{2}{*}{7.2} & 2.5 & 9.85 & 105 \\
\hline & & 10 & 16.4 & 92 \\
\hline \multirow{2}{*}{ aTHE } & \multirow{2}{*}{ ND } & 2.5 & 1.9 & 76 \\
\hline & & 10 & 8.9 & 89 \\
\hline \multirow{2}{*}{ THE } & \multirow{2}{*}{4.8} & 2.5 & 6.8 & 79 \\
\hline & & & 15.0 & 102 \\
\hline \multirow{2}{*}{$\mathrm{DX}$} & \multirow{2}{*}{ ND } & 2.5 & 2.1 & 84 \\
\hline & & 10 & 10.8 & 108 \\
\hline
\end{tabular}

Standard solutions (spike) were added to a urine sample with predetermined corticosteroid levels. The resulting concentration of the mixture (urine + spike) was determined. The concentrations presented are means of triplicate analysis. 
Table 4. Concentrations of corticosteroids in control bovine urine collected during the experiment. Data are reported as the median ( $\mathrm{ng} \mathrm{mL}$ ) with corresponding $25^{\text {th }}-75^{\text {th }}$ percentile. Number of samples/number of positive findings are given in parenthesis.

\begin{tabular}{|c|c|c|c|c|c|}
\hline Corticosteroids & Day 0 & Day 15 & Day 29 & Day 40 & $\begin{array}{l}\text { Statistical } \\
\text { differences }\end{array}$ \\
\hline \multirow{3}{*}{ THF } & 13.00 & 17.75 & 17.26 & 12.36 & \\
\hline & 7.91-23.04 & $8.42-49.22$ & $7.54-24.03$ & $9.78-17.43$ & \\
\hline & $(8 / 8)$ & $(8 / 8)$ & $(8 / 8)$ & $(8 / 8)$ & \\
\hline \multirow{3}{*}{ THE } & 6.65 & 6.99 & 7.20 & 15.42 & \\
\hline & $2.74-9.70$ & $2.77-14.95$ & $1.80-10.89$ & $9.15-22.38$ & NS \\
\hline & $(8 / 8)$ & $(8 / 8)$ & $(8 / 8)$ & $(8 / 8)$ & \\
\hline \multirow{3}{*}{ THF/THE } & 2.36 & 3.04 & 2.76 & $0.94^{a, b, c}$ & \\
\hline & $1.65-3.82$ & $2.50-3.89$ & $2.21-4.18$ & $0.71-1.13$ & $P=0.003$ \\
\hline & $(8 / 8)$ & $(8 / 8)$ & $(8 / 8)$ & $(8 / 8)$ & \\
\hline \multirow{3}{*}{$\mathbf{F}$} & 3.70 & 4.07 & 1.7 & 3.13 & \\
\hline & $1.42-5.80$ & $2.82-5.27$ & $1.77-3.80$ & $2.71-6.55$ & NS \\
\hline & $(8 / 8)$ & $(8 / 8)$ & $(8 / 5)$ & $(8 / 8)$ & \\
\hline \multirow{3}{*}{$\mathbf{E}$} & 6.99 & 9.89 & $3.28^{d}$ & $2.18^{a}$ & \\
\hline & $2.29-9.15$ & $6.29-13.34$ & $1.56-9.13$ & $1.60-3.01$ & $P=0.011$ \\
\hline & (8) & (8) & (8) & (8) & \\
\hline \multirow{3}{*}{$F / E$} & 0.65 & 0.41 & 0.53 & $1.78^{a, b, c}$ & \\
\hline & $0.53-0.69$ & $0.39-0.44$ & $0.45-3.76$ & $1.47-2.25$ & $P=0.003$ \\
\hline & $(8 / 8)$ & $(8 / 8)$ & $(8 / 5)$ & $(8 / 8)$ & \\
\hline \multirow{3}{*}{ PL } & 0 & 0.72 & 0.74 & & \\
\hline & 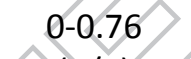 & $0.63-0.79$ & $0-1.32$ & $(8 / 0)$ & NS \\
\hline & & $(8 / 7)$ & $(8 / 5)$ & & \\
\hline \multirow[t]{4}{*}{ PN } & & 0 & 5.6 & 0 & NP \\
\hline & $(8 / 0)$ & $(8 / 8)$ & $(8 / 1)$ & $(8 / 0)$ & \\
\hline & 0 & 0 & 0 & 0 & NP \\
\hline & $(8 / 0)$ & $(8 / 0)$ & $(8 / 0)$ & $(8 / 0)$ & \\
\hline
\end{tabular}

NS - not significant, NP - not performed

Friedman Repeated Measures Analysis of Variance on Ranks was used to test the significance between the groups. When the analysis was significant, to isolate the group that differs from the others, pairwise multiple comparison procedures (Tukey's Test) were applied. Following subscripts refer to statistically significant pairwise difference: ${ }^{a}$ Day 0 vs Day $40 ;{ }^{b}$ Day 15 vs Day 40; ${ }^{\text {c }}$ Day 29 vs Day 40; ${ }^{\text {Day }} 0$ vs Day 29 
Table 5. Urinary concentrations of corticosteroids collected during prednisolone treatment. Data are reported as the median ( $\mathrm{ng} \mathrm{mL} \mathrm{m}^{-1}$ ) with corresponding $25^{\text {th }}-75^{\text {th }}$ percentiles. Number of samples/number of positive findings are given in parenthesis.

\begin{tabular}{|c|c|c|c|c|c|}
\hline Corticosteroids & Day 0 & Day 15 & Day 29 & Day 40 & $\begin{array}{l}\text { Statistical } \\
\text { differences }\end{array}$ \\
\hline \multirow{3}{*}{ THF } & 14.26 & 6.18 & $2.90^{a}$ & $2.40^{b}$ & \\
\hline & $8.06-18.62$ & $4.74-8.75$ & $1.11-4.87$ & $1.96-6.94$ & \\
\hline & $(6 / 6)$ & $(6 / 6)$ & $(6 / 6)$ & $(6 / 6)$ & \\
\hline \multirow{3}{*}{ THE } & 11.93 & 3.86 & 2.40 & 4.40 & \\
\hline & $5.73-20.31$ & $1.87-4.80$ & $2.01-3.30$ & $1.9-6.9$ & NS \\
\hline & $(6 / 6)$ & $(6 / 6)$ & $(6 / 6)$ & $(6 / 6)$ & \\
\hline \multirow{3}{*}{ THF/THE } & 1.09 & 2.10 & 0.74 & 1.10 & \\
\hline & $0.79-2.66$ & $1.48-4.80$ & $0.53-1.93$ & $0.54-1.26$ & NS \\
\hline & $(6 / 6)$ & $(6 / 6)$ & $(6 / 6)$ & $(6 / 6)$ & \\
\hline \multirow{3}{*}{$F$} & 4.41 & 1.07 & & $b^{b}$ & \\
\hline & $2.69-8.27$ & $0.91-1.28$ & & & $P=0.001$ \\
\hline & $(6 / 6)$ & $(6 / 6)$ & & $(6 / 0)$ & \\
\hline \multirow{3}{*}{ E } & 4.27 & 1.49 & & $0^{b}$ & \\
\hline & $1.83-8.25$ & $1.01-2.04$ & (c) & 0 & $P=0.001$ \\
\hline & $(6 / 6)$ & $(6 / 6)$ & $(6 / 0)$ & & \\
\hline \multirow{3}{*}{$F / E$} & 1.66 & 0.76 & $\pi$ & & \\
\hline & $0.44-2.33$ & $0.66-0.97$ & / & / & NP \\
\hline & & $(6 / 6)$ & & & \\
\hline \multirow{7}{*}{ PL } & & 0.67 & $2.48^{a}$ & $0.39^{c}$ & \\
\hline & & $0.46-1.19$ & $1.05-6.18$ & $0-1.07$ & $P=0.001$ \\
\hline & & $(6 / 5)$ & $(6 / 6)$ & $(6 / 3)$ & \\
\hline & & 0 & 0.80 & 0 & \\
\hline & $(6 / 0)$ & $(6 / 0)$ & $0-2.34$ & $(6 / 0)$ & NS \\
\hline & & & $(6 / 3)$ & & \\
\hline & $\begin{array}{c}\mathbf{0} \\
(6 / 0) \\
\end{array}$ & $\begin{array}{c}0 \\
(6 / 0)\end{array}$ & $\begin{array}{c}\mathbf{0} \\
(6 / 0) \\
\end{array}$ & $\begin{array}{c}0 \\
(6 / 0)\end{array}$ & NP \\
\hline
\end{tabular}

NS - not significant; NP - not performed

Friedman Repeated Measures Analysis of Variance on Ranks was used to test the significance between the groups. When the analysis was significant, to isolate the group that differs from the others, pairwise multiple comparison procedures (Tukey's Test) were applied. Following subscripts refer to statistically significant pairwise difference: ${ }^{\mathbf{a}}$ Day 0 vs Day $29 ;^{\mathbf{b}}$ Day 0 vs Day 40; c Day 29 vs Day 40 
Table 6. Urinary concentrations of corticosteroids collected during dexamethasone treatment. Data are reported as the median ( $\mathrm{ng} \mathrm{mL}^{-1}$ ) with corresponding $25^{\text {th }}-75^{\text {th }}$ percentiles. Number of samples/number of positive findings are given in parenthesis.

\begin{tabular}{|c|c|c|c|c|c|}
\hline Corticosteroids & Day 0 & Day 15 & Day 29 & Day 40 & $\begin{array}{l}\text { Statistical } \\
\text { difference }\end{array}$ \\
\hline THF & $\begin{array}{c}\mathbf{1 9 . 2 1} \\
10.86-25.1 \\
(5 / 5) \\
\end{array}$ & $\begin{array}{c}18.83 \\
5.41-29.34 \\
(5 / 5) \\
\end{array}$ & $\begin{array}{c}0^{a} \\
(5 / 0)\end{array}$ & $\begin{array}{l}0^{b, d} \\
(5 / 0)\end{array}$ & $\begin{array}{l}0.0 \\
\end{array}$ \\
\hline THE & $\begin{array}{c}10.25 \\
8.41-16.61 \\
(5 / 5) \\
\end{array}$ & $\begin{array}{c}9.09 \\
1.24-14.25 \\
(5 / 5) \\
\end{array}$ & $\begin{array}{l}0^{a, c} \\
(5 / 0)\end{array}$ & $\begin{array}{c}\mathbf{5 . 0 8} \\
4.00-5.51 \\
(5 / 5) \\
\end{array}$ & $P=0.011$ \\
\hline THF/THE & $\begin{array}{c}1.76 \\
0.99-2.24 \\
(5 / 5)\end{array}$ & $\begin{array}{c}\mathbf{2 . 3 1} \\
1.93-8.06 \\
(5 / 5)\end{array}$ & / & & NP \\
\hline $\mathbf{F}$ & $\begin{array}{c}4.40 \\
3.50-9.90 \\
(5 / 5) \\
\end{array}$ & $\begin{array}{c}1.00 \\
0.81-9.22 \\
(5 / 5) \\
\end{array}$ & a, $(5 / 0)$ & & $P<0.001$ \\
\hline E & $\begin{array}{c}4.30 \\
1.30-8.21 \\
(5 / 5)\end{array}$ & $\begin{array}{c}1.30 \\
0.73-1.94 \\
(5 / 5) \\
\end{array}$ & $\begin{array}{l}0^{a, c} \\
(5 / 0)\end{array}$ & $\begin{array}{l}0^{b, d} \\
(5 / 0)\end{array}$ & $P<0.003$ \\
\hline$F / E$ & $\begin{array}{c}\mathbf{0 . 4 3} \\
0.99-2.24 \\
(5 / 5) \\
\end{array}$ & $\begin{array}{c}\mathbf{0 . 9 3} \\
0.37-1.45 \\
(5 / 5) \\
\end{array}$ & $V_{1}$ & / & NP \\
\hline PL & 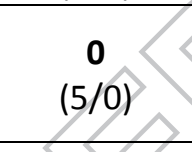 & $\begin{array}{c}0 \\
(5 / 0)\end{array}$ & $\begin{array}{c}\mathbf{0 . 6 6} \\
0-1.24 \\
(5 / 3) \\
\end{array}$ & $\begin{array}{c}0 \\
(5 / 0)\end{array}$ & $P=0.029$ \\
\hline PN & & $\begin{array}{c}\mathbf{0} \\
(5 / 0)\end{array}$ & $\begin{array}{c}\mathbf{0} \\
(5 / 0)\end{array}$ & $\begin{array}{c}\mathbf{0} \\
(5 / 0)\end{array}$ & NP \\
\hline & $\begin{array}{c}0 \\
(5 / 0)\end{array}$ & $\begin{array}{c}0 \\
(5 / 0)\end{array}$ & $\begin{array}{c}1.65^{\mathrm{a}, \mathrm{c}} \\
1.47-1.71 \\
(5 / 5)\end{array}$ & $\begin{array}{c}1.46^{b, d} \\
1.32-1.60 \\
(5 / 5)\end{array}$ & $P=0.003$ \\
\hline
\end{tabular}

NS - not significant; NP - not performed

Friedman Repeated Measures Analysis of Variance on Ranks was used to test the significance between groups.

When the analysis was significant, to isolate the group that differs from the others, pairwise multiple comparison procedures (Tukey's Test) were applied. Following subscripts refer to statistically significant pairwise difference: ${ }^{a}$ Day 0 vs Day $29 ;{ }^{\mathbf{b}}$ Day 0 vs Day $40 ;{ }^{\mathbf{C}}$ Day 15 vs Day $29 ;^{\text {C }}$ Day 15 vs Day 40 
Graphical Abstract

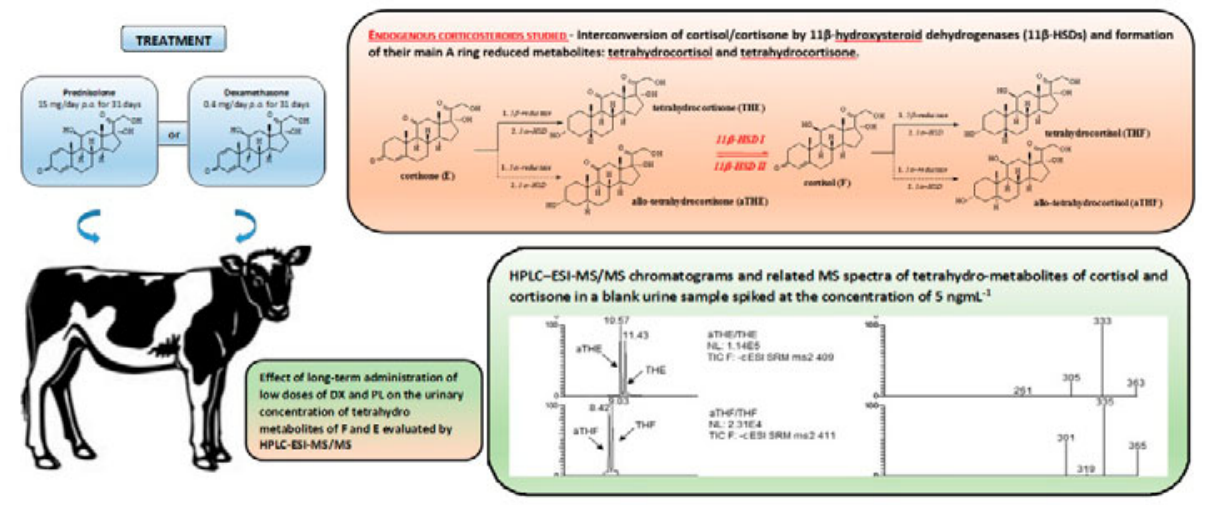

